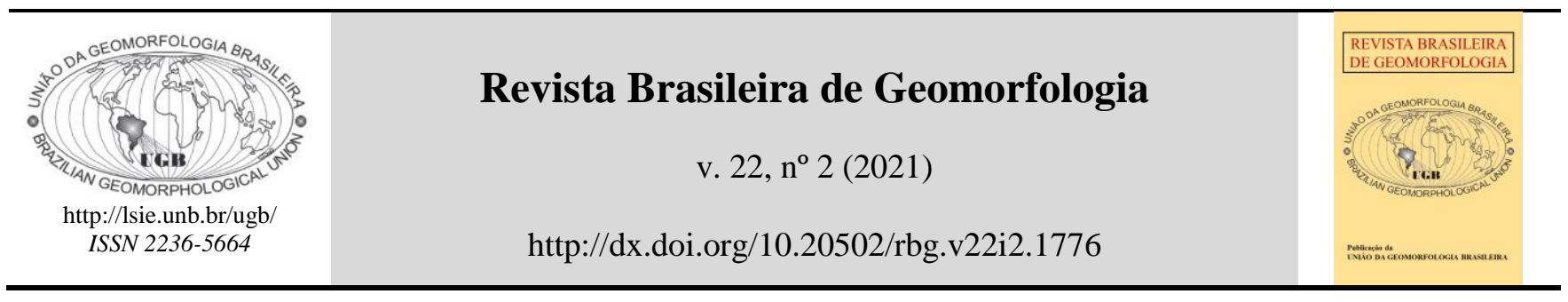

Artigo de Pesquisa

\title{
Modelagem espacial da neotectônica na costa do descobrimento, sul do estado da Bahia
}

\section{Spatial modeling of neotectonics on the discovery coast, south of the state of Bahia}

\section{Oriana Isabel Rojas González ${ }^{1}$ e Carlos César Uchôa de Lima ${ }^{2}$}

1 Pós-graduação em Modelagem em Ciências da Terra e do Ambiente/UEFS. Av. Transnordestina S/N, Bairro Novo Horizonte, Feira de Santana, Bahia. CEP: 44036-900. Brasil. E-mail: orianarojasgonzalez@gmail.com.

ORCID: https://orcid.org/0000-0002-1675-2333

2 PPGM/ Universidade Estadual de Feira de Santana. Av. Transnordestina S/N, Bairro Novo Horizonte, Feira de Santana, Bahia. CEP: 44036-900. Brasil.E-mail: uchoamaster@gmail.com.

ORCID: https://orcid.org/0000-0002-3499-3560

Recebido: 10/10/2019; Aceito: 30/12/2020; Publicado: 10/04/2021

\begin{abstract}
Resumo: Este trabalho objetiva realizar a modelagem da atuação da neotectônica presente na Costa do Descobrimento, sul do estado da Bahia, onde afloram sedimentos do Neógeno que constituem a Formação Barreiras. A área de estudos possui uma geomorfologia dominada por tabuleiros que, ao atingirem a costa, formam falésias com até $40 \mathrm{~m}$ de altura. Estudos de campo foram desenvolvidos com o intuito de observar, descrever, medir e interpretar as estruturas geológicas, principalmente juntas e falhas que indicassem a ação da Neotectônica. A partir de dados de elevação de MDT/SRTM processados através de Sistemas de Informação Geográfica (SIG), utilizando software ArcMap, foi realizado um conjunto de mapas temáticos, destacando os índices estruturais (mapa de lineamentos, densidade de lineamentos e frequência de lineamentos), índices geomorfológicos (densidade de drenagem, frequência de fluxo e índice topográfico de umidade) e índices morfotectônicos (amplitude de relevo e gradiente de inclinação) para que, mediante a técnica de combinação linear ponderada (WLC), se determinasse áreas que guardassem registros da tectônica mais recente. Os dados de campo, e a análise das imagens demonstram uma maior densidade de lineamentos, na direção NW-SE, e, secundariamente na direção NE-SW, totalizando 908 e 722 respectivamente. O mapa originado destaca registros mais evidentes da Neotectônica, nas bacias dos Rios Camurugi, Trancoso e Caraíva, evidenciados pelo basculamento de blocos estruturais e modificação nas direções de drenagem. A integração dos mapas destacando os índices estruturais, geomorfológicos e morfotectônicos mostra ser um método eficaz para a modelagem de eventos tectônicos e ratifica a ação da Neotectônica na Costa Descobrimento, abrindo possibilidades para que outros estudos possam se desenvolver ao longo da costa leste do Brasil.
\end{abstract}

Palavras-chave: Neotectônica; Formação Barreiras; Índices Geomorfológicos; índices Estruturais.

\begin{abstract}
This work aims to model neotectonics events present on the Discovery Coast, southern Bahia State, where Neogene sediments of the Barreiras Formation outcrop. The study area is dominated by tablelands that reach the coast, originating sea cliffs up to $40 \mathrm{~m}$ high. Field studies were developed in order to observe, describe, measure and interpret geological structures, especially joints and faults that indicate the action of neotectonics. From the MDT/SRTM data, processed through Geographic Information Systems (GIS) using ArcMap, a set of thematic maps was made, highlighting the structural indices (lineament map, lineament density and lineament frequency), geomorphological indices (drainage density, flow frequency and humidity topographic index) and morphotectonic indices (relief amplitude and slope gradient). In addition, it was applied the weighted linear combination technique (WLC), identifying areas that would keep records of the most recent tectonic action. Field data and image analysis demonstrated a higher density of lineaments in the NW-SE and secondarily in the
\end{abstract}


NE-SW direction totaling 908 and 722 respectively. The originated map highlights a stronger action of the neotectonics in the Camurugi, Trancoso and Caraíva basins, evidenced by structural block tilting and modification of drainage patterns. The integration of the maps highlighting the structural, geomorphological and morphotectonic indices, proved to be an effective method for modeling tectonic events, confirming the neotectonics action on the Discovery Coast and opening possibilities for further studies to develop along the eastern Brazilian Coast.

Keywords: Neotectonics; Barreiras Formation; Gemorphological Indexes; Structural Indexes.

\section{Introdução}

A Neotectônica compreende a um conjunto de processos, que tem modelado várias feições morfológicas do Neógeno ao Recente (OBRUCHEV, 1948, apud SUGUIO; MARTIN, 1996). Na década de 1980, o conceito de neotectônica, passou a englobar eventos tectônicos jovens, que ocorreram ou ainda estão ocorrendo em uma região qualquer, após sua orogênese ou após o seu reajustamento tectônico mais significativo (PAVLIDES, 1989).

No Brasil, a influência da Neotectônica na configuração da morfologia do relevo ainda é motivo de muito debate, já que o nosso país está bordejado por uma margem continental do tipo Atlântica (passiva), que se constitui em uma região considerada estável (BEZERRA; VITA-FINZI, 2000). Apesar de vários autores enfatizarem uma "tectônica moderna" em território brasileiro, desde a década de 1950 (FREITAS, 1951; KING, 1956), somente a partir da década de 1980, é que esse pensamento foi sendo modificado, quando uma grande quantidade de sismos passou a ser registrada com maior frequência na Região Nordeste do Brasil (HASUÍ, 1990; LIMA, 2000).

Vários estudos abordam a Neotectônica baseando-se na morfotectônica (HASUÍ, 1990; SAADI, 2000; COSTA et al., 2001; LIMA; VILAS BOAS; BEZERRA, 2006; LIMA et al., 2014) e, outros autores, levam em consideração o registro e medição de estruturas geológicas que indiquem a atuação da tectônica em uma determinada área, tais como juntas, falhas e, no caso de sedimentos inconsolidados, os sismitos (BEZERRA et al., 2005; LIMA, 2010 ). Muitos desses estudos foram realizados a partir de estruturas presentes nos sedimentos da Formação Barreiras, que é um complexo sedimentar depositado no Neógeno, apresentando um relevante significado tectônico (HASUÍ, 1990; LIMA, 2000; ROSSETTI; BEZERRA; DOMINGUEZ, 2013).

As atividades tectônicas pós-Mioceno podem explicar, dentre outras questões, o porquê de a Formação Barreiras possuir altitudes tão distintas ao longo da costa brasileira (ROSSETTI et al.,2013). Outras evidências dos movimentos neotectônicos são ainda encontradas em vários pontos de ocorrência da Formação Barreiras, onde a drenagem encontra-se fortemente encaixada nos lineamentos (LIMA; VILAS BOAS; BEZERRA, 2006).

Adicionalmente, muitas pesquisas têm abordado o estudo geomorfológico e morfotectônico dos sistemas de drenagem, que podem fornecer indicadores úteis sobre o recente regime tectônico de uma região. A aplicação desses índices podem evidenciar a ação da Neotectônica, a partir da identificação de áreas deformadas por processos tectônicos recentes (BULL; MCFADDEN, 1977; KELLER, 1986; AYALEW; YAMAGISHI; UGAWA, 2004; PÉREZ-PEÑA et al., 2009; ARGYRIOU et al., 2015).

Valiosas informações obtidas a partir de índices geomorfológicos e morfotectônicos têm sido reveladas em estudos de áreas tectonicamente ativas, destacando as pesquisas realizadas no sudoeste dos EUA (BULL; MCFADDEN, 1977; ROCKWELL; KELLER; JOHNSON, 1984; KELLER, 1986), no grabenAcambay, no México (RAMÍREZ-HERRERA, 1998), na costa do Pacífico da Costa Rica (WELLS et al., 1988), na costa Sudeste da Espanha (SILVA et al., 2003), nas montanhas dos Apeninos na Itália (TROIANI; DELLA SETA, 2008), na Grécia central (TSODOULOS; KOUKOUVELAS; PAVLIDES, 2008) e no oeste de Creta, Grécia (ARGYRIOU et al., 2015).

Esta pesquisa visa modelar a ação da Neotectônica, na Costa do Decobrimento, sul do estado da Bahia, levando em consideração dados de elevação de MDT/SRTM, processados através de Sistemas de Informação Geográfica (SIG). Foi utilizado o software ArcMap para a confecção de um conjunto de mapas temáticos, como índices estruturais (mapa de lineamentos, densidade de lineamentos e frequência de lineamentos), índices geomorfológicos (densidade de drenagem, frequência de fluxo e índice topográfico de umidade) e índices morfotectônicos (amplitude de relevo e gradiente de inclinação) para que, mediante a técnica de combinação linear ponderada (WLC), se identificassem as áreas que registraram a ação da tectônica desenvolvida a partir do Neógeno. 


\section{2. Área de Estudo}

A área de estudo (Figura 1) está localizada na parte sul do Estado da Bahia, compreendendo parte da região geográfica e socioeconômica denominada de Costa do Descobrimento, que está inserida nos municípios de Santa Cruz Cabrália, Porto Seguro e Prado. A Costa do Descobrimento configura-se como um sítio de grande importância histórica e cultural, já que foi a primeira porção de terra do Brasil avistada pelos navegadores portugueses, quando alcançaram a costa da América do Sul em 1500.

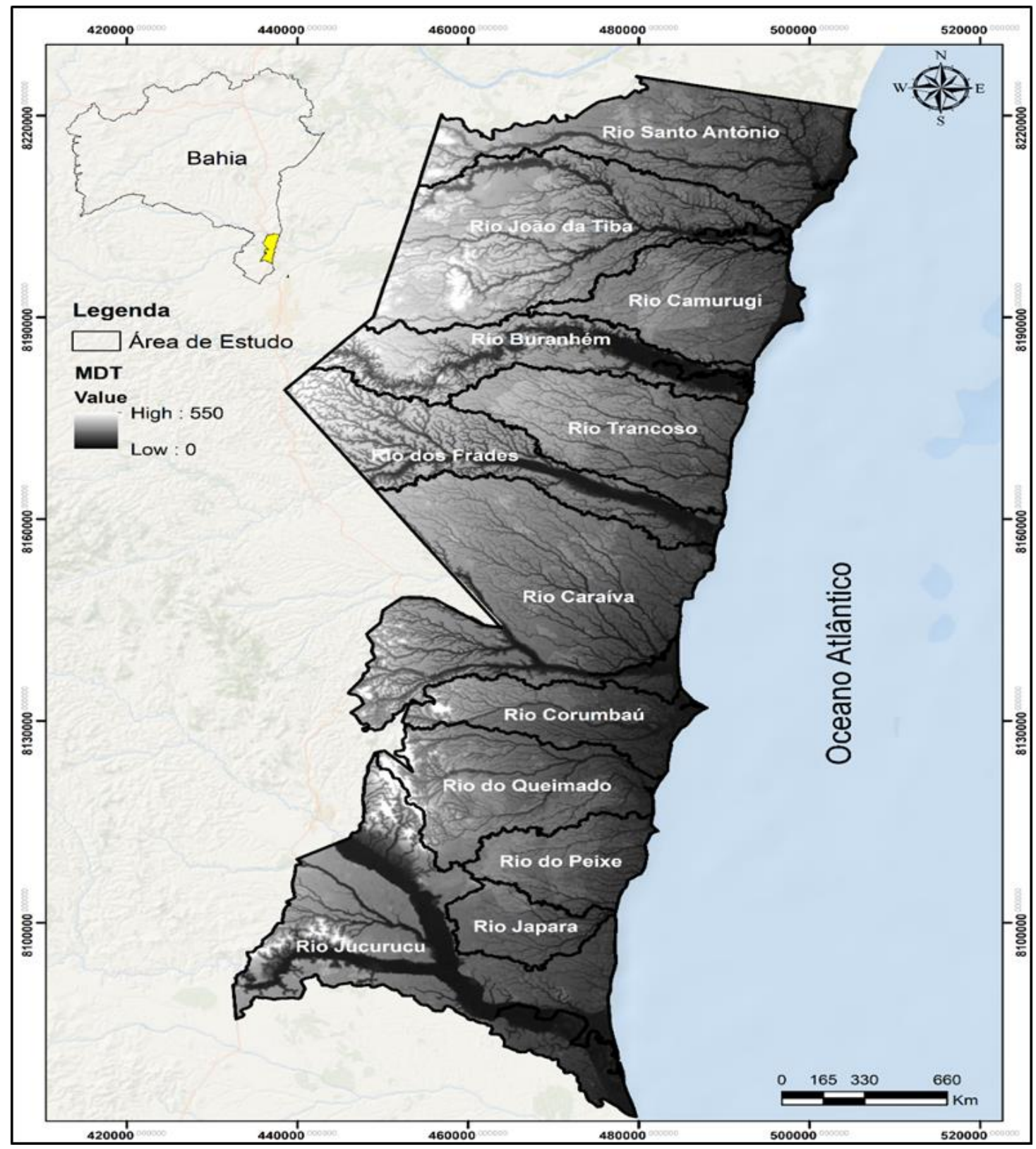

Figura 1. Mapa de localização da área de estudos, com o delineamento das bacias hidrográficas.

Na Costa do Descobrimento os rios Buranhém (Porto Seguro) e João de Tiba (Santa Cruz Cabrália) são os mais importantes, tanto pelo aspecto histórico e cultural, quanto pelo papel socioeconômico por eles representados. Outras importantes bacias são as dos Rios Santo Antônio, Frades, Caraíva, Corumbau, Camurugi, Trancoso, Queimado, Peixe, Japara e Jucuruçu. A rede hidrográfica intermitente é relativamente densa, refletindo os fatores climáticos. As regiões dos Rios Santo Antônio e os seus afluentes (Rios Braço do Norte e Braço do Sul), João de Tiba, Buranhém, dos Frades, Caraíva e Corumbau apresentam regime fluvial perene (DOMINGUEZ, 1983).

Em relação à geologia os principais tipos litológicos presentes na Costa do Descobrimento podem ser agrupados em três províncias principais. A primeira delas é o embasamento, composto por rochas do 
Precambriano (gnaisses, gnaisses migmatíticos, gnaisses kinzigíticos, quartzitos, xistos, filitos, metacarbonatos, conglomerados e granitóides), que afloram na porção mais ocidental da região (NEVES; SOARES; MARCIANO, 1986; CHANG et al., 1992). Em seguida vem os Tabuleiros Costeiros, constituídos por sedimentos do Neógeno, onde predomina uma intercalação de arenitos e lamitos, sobrepondo a arcósios (LIMA; VILAS BOAS; BEZERRA, 2006), ocupando a maior parte da área e alcançam a linha de costa em vários trechos. Por fim, as Planícies Quaternárias, constituídas por sedimentos marinhos transicionais, depósitos de origem continental e recifes de coral (LIMA; DOMINGUEZ, 2015).

As colinas e serras que formam o embasamento cristalino na Costa do Descobrimento integram a Província Pegmatítica Oriental do Brasil (NEVES; SOARES; MARCIANO, 1986). Essas rochas foram formadas durante o ciclo tectônico Transamazônico (920 Ma), sendo constituídas por migmatitos, granulitos e granitoides (CHANG et al., 1992), com inserções de rochas ígneas graníticas, durante o Brasiliano (570-540 Ma) (NEVES; SOARES; MARCIANO, 1986).

Os Tabuleiros Costeiros variam em largura entre 20 e $100 \mathrm{~km}$ e exibem terreno plano com um leve gradiente em direção ao mar. Quando os tabuleiros chegam ao litoral, eles formam falésias ativas dispostas em vários quilômetros de comprimento e atingem até $40 \mathrm{~m}$ de altura. Dentro dessas seções, falésias inativas cobertas com vegetação ocorrem onde as praias são mais largas. Vales largos, baixos, flanqueados por paredes íngremes e com rios fluindo para o oceano, cortam a superfície plana dos tabuleiros (LIMA; VILAS BOAS; BEZERRA, 2006; LIMA; DOMINGUEZ, 2015).

As planícies quaternárias ocupam as porções mais baixas da área de estudo bordejando a linha de costa e adentrando os grandes vales, que marcam o abatimento dos tabuleiros costeiros, representando grabens por onde correm os maiores rios, dispostos transversalmente à linha de costa (LIMA; VILAS BOAS; BEZERRA, 2006). As planícies quaternárias se sobrepõem discordantemente à Formação Barreiras. Esses depósitos tiveram sua acumulação controlada pelas variações do nível relativo do mar que afetaram a costa brasileira durante o Quaternário (CBPM, 2000).

\section{Materiais e Métodos}

As etapas desta pesquisa envolveram: trabalhos de campo, análise de imagens do Shuttle Radar Topography Mission (SRTM) para a elaboração de mapas temáticos, análise dos dados e a confecção do produto final, que foi o mapa de modelagem da deformação neotectônica.

\subsection{Trabalhos de Campo:}

Nos trabalhos de campo, foram utilizadas as técnicas clássicas como identificação e medida das estruturas geológicas com a bússola geológica, ao longo das falésias constituídas por sedimentos da Formação Barreiras. Os pontos visitados foram localizados com GPS e integrados no banco dos dados, utilizando o Sistema de Informação Geográfica (SIG). Todos os dados levantados em campo foram sistematizados em tabelas, gerando os diagramas de roseta, utilizando-se o software StereoNett 2.45.

\subsection{Elaboração de Mapas Temáticos}

\subsection{1 Índices estruturais}

Os índices estruturais estão representados na nossa pesquisa pelos mapas de lineamentos (L), densidade de lineamentos (DL) e frequência de lineamentos (FL). A interpretação dos lineamentos foi centrada na associação entre feições negativas e positivas do relevo, marcadoras dos lineamentos estruturais como, por exemplo, o padrão de drenagem e alinhamento dos segmentos de canais fluviais e quebras de falésias, sendo estes normalmente considerados excelentes indicadores dos sítios preferenciais de deformação Neotectônica (FONSECA, 2006).

O mapa de lineamentos foi desenvolvido com imagens obtidas pelo satélite Landsat 8, com a função de mapa de relevo sombreado (Hillshade), conforme diferentes azimutes de iluminação $\left(130^{\circ}, 165^{\circ}\right.$, e $225^{\circ}$ e inclinação de $45^{\circ}$ ) escolhidos para enfatizar os alinhamentos, seguindo os seguintes critérios: (1) Alinhamento significativo de um mesmo curso d'água ou de trecho com vários quilômetros que determina um traçado de falha importante; (2) A repetitividade de trechos fluviais retilíneos ao longo de uma faixa de terreno bem delimitada, levando em consideração que essa característica expressa a influência de uma zona de falha e/ou juntas tectônicas; (3) As 
variações bruscas na orientação dos fluxos hidrológicos entre grupos de microbacias adjacentes, tomando como premissa que essas mudanças bruscas indicam basculamento dos blocos estruturais analisados (LIMA; VILAS BOAS; BEZERRA, 2006; LIMA; DOMINGUEZ, 2015). Os dados de lineamentos foram processados pela ferramenta complementar AzimuthFinder (QUEIROZ et al., 2014), instalada no ArcGIS, que devolve informações de orientação, gerando uma matriz de dados de frequência. A matriz foi então espacializada em gráficos do tipo rosetas no StereoNett2.45.

Os mapas de densidade de lineamentos (DL) e de frequência de lineamentos (FL) foram elaborados no software ArcGIS, englobando todas as direções, utilizando a ferramenta LineDensity e KernelDensity, respectivamente, presente no ArcToolbox, com tamanho de célula 30 e unidade medida em $\mathrm{km} / \mathrm{km}^{2}$.

Os mapas de densidade de lineamentos (DL) e de frequência de lineamentos (FL) são muito úteis para avaliar a atividade tectônica, pois zonas com alta DL e FL podem identificar as regiões com graus de fratura, propagação de falhas e a influência do controle neotectônico (ANANABA; ANJAKAIYE, 1987; SELEEM, 2013). Em nossa área de estudo, essas feições estão representadas por juntas e falhas observadas nos sedimentos do Neógeno, da Formação Barreiras e dos lineamentos que controlam as planícies quaternárias. O mapa DL quantifica o comprimento total de lineamentos por $\mathrm{km}^{2}$ e $\mathrm{FL}$ quantifica o número total de lineamentos da área estudada (BRIERE; SCANLON, 2000; DINESH et al., 2014).

\subsection{2. Índices Geomorfológicos}

Os índices geomorfológicos (Tabela 1) são utilizados para identificar redes de drenagem que reagiram ao efeito da tectônica ativa. Esses índices incluem: densidade de drenagem (Dd), fluxo de frequência $(\mathrm{Fu})$ e índice topográfico de umidade (TWI) (BULL; MCFADDEN, 1977; MOLIN; PAZZAGLIA; DRAMIS, 2004; TOUDESHKI; ARIAN, 2011). A partir desses índices, é possível avaliar os tipos de características do fluxo associados à deformação neotectônica, como a mudança de canal e gradiente de vale, ou mudança de largura e profundidade do canal (SUMMERFIELD, 2000).

Tabela 1. Índices geomorfológicos

\begin{tabular}{|c|c|c|c|c|}
\hline Índice & Equação & Conceito & Importância & Autores \\
\hline $\begin{array}{c}\text { Mapa de } \\
\text { densidade } \\
\text { de } \\
\text { drenagens } \\
\text { (Dd) }\end{array}$ & $\begin{array}{c}D d=\frac{\Sigma \mathrm{L}}{\mathrm{A}} \\
D d: \text { densidade de } \\
\text { drenagem } \\
\Sigma L: \text { soma do } \\
\text { comprimento dos canais } \\
A: \text { a área da bacia }\end{array}$ & $\begin{array}{c}\text { Permite a } \\
\text { individualização de áreas } \\
\text { anômalas de alta ou baixa } \\
\text { densidade de drenagem, } \\
\text { que podem estar } \\
\text { refletindo controle } \\
\text { tectônico. }\end{array}$ & $\begin{array}{c}\text { Os valores altos de Dd } \\
\text { caracterizam a ação da } \\
\text { Neotectônica, sobre } \\
\text { sedimentos depositados } \\
\text { do Neógeno ao } \\
\text { Quaternário. }\end{array}$ & $\begin{array}{l}\text { Horton (1945), Berger } \\
\text { e Entekhabi (2001) e } \\
\text { Awasthi et al. (2002). }\end{array}$ \\
\hline $\begin{array}{l}\text { Mapa de } \\
\text { Frequência } \\
\text { de Fluxo } \\
\text { (Fu) }\end{array}$ & $\begin{array}{c}F u=N / A \\
N \text { :número total de } \\
\text { segmentos de Fluxo } \\
\text { A:área da bacia. }\end{array}$ & $\begin{array}{l}\text { Os valores da frequência } \\
\text { do fluxo indicam grau de } \\
\text { inclinação, } \\
\text { permeabilidade da rocha } \\
\text { e superfície escoamento. }\end{array}$ & $\begin{array}{l}\text { Os valores elevados de } \\
\text { Fu indicam que a rede } \\
\text { de drenagem se } \\
\text { desenvolve sob } \\
\text { influência tectônica. }\end{array}$ & $\begin{array}{l}\text { Horton (1945), e } \\
\text { Kouli et al. (2007). }\end{array}$ \\
\hline $\begin{array}{c}\text { Índice } \\
\text { topográfico } \\
\text { de umidade } \\
\text { (TWI) }\end{array}$ & $\begin{array}{c}\text { AS: é a área de } \\
\text { contribuição } \\
\text { Tanb: é a inclinação local. }\end{array}$ & $\begin{array}{c}\text { Indica características de } \\
\text { relevo controlado por } \\
\text { falhas, em depressões } \\
\text { lineares conectando vales, } \\
\text { com a erosão atuando em } \\
\text { zonas de fraqueza } \\
\text { estrutural. }\end{array}$ & $\begin{array}{l}\text { Valores baixos de TWI } \\
\text { indicam baixa } \\
\text { acumulação de fluxo, } \\
\text { vales em forma de V e } \\
\text { alta influência tectônica. }\end{array}$ & $\begin{array}{l}\text { Beven e Kirkby } \\
\text { (1979) e Schmidt e } \\
\text { Persson (2003). }\end{array}$ \\
\hline
\end{tabular}




\subsection{3. Índices morfotectônicos}

Os Indices morfotectônicos (Tabela 2) têm desempenhado um papel fundamental na determinação da atividade tectônica, principalmente na identificação e no mapeamento de falhas, ou na avaliação da migração e identificação de regiões inclinadas ou elevadas. Os índices incluem amplitude de relevo (AR) e gradiente de inclinação (S) (KELLER, 1986; VAN DER BEEK; CHAMPEL; MUGNIER, 2002; SILVA et al., 2003).

Tabela 2. Indices morfotectônicos

\begin{tabular}{|c|c|c|c|c|}
\hline Índice & Equação & Conceito & Importância & Autores \\
\hline $\begin{array}{l}\text { Amplitude } \\
\text { de relevo } \\
\text { (Ar) }\end{array}$ & $\begin{array}{c}A r=A m a x-A m i n \\
\text { Amax }: \text { Amplitude } \\
\text { Maxima } \\
\text { Amin: Amplitude } \\
\text { Minima }\end{array}$ & $\begin{array}{l}\text { É utilizado para a configuração } \\
\text { estatisticamente orográfica da } \\
\text { área de estudo para determinar a } \\
\text { erosão fluvial. }\end{array}$ & $\begin{array}{l}\text { Representa a distribuição de } \\
\text { tectônica ativa através da } \\
\text { avaliação do relevo relativo de } \\
\text { uma região }\end{array}$ & $\begin{array}{l}\text { Della Seta et al. } \\
\text { (2004) e Troiani e } \\
\text { Della Seta (2008). }\end{array}$ \\
\hline $\begin{array}{l}\text { Gradiente de } \\
\text { inclinação } \\
\text { (S) }\end{array}$ & $\begin{array}{c}S=\sqrt{\left(G^{2}+H^{2}\right)} \\
G \text { : gradiente leste-oeste } \\
H: \text { gradiente norte-sul. }\end{array}$ & $\begin{array}{l}\text { Mostra a inclinação máxima da } \\
\text { declividade, indicando a } \\
\text { mudança na elevação entre cada } \\
\text { célula e seus vizinhos. }\end{array}$ & $\begin{array}{l}\text { Movimentos de inclinação, ou } \\
\text { elevação é causado pela } \\
\text { atividade tectônica. }\end{array}$ & $\begin{array}{l}\text { Evans (1979) e } \\
\text { Panizza (1996). }\end{array}$ \\
\hline
\end{tabular}

\subsection{Análise dos Dados}

A análise dos dados foi realizada mediante à utilização do Sistema de Informação Geográfica (SIG), integrando dados de um processo de hierarquia analítica (AHP) e uma combinação linear ponderada (WLC) para processar dados de múltiplos critérios.

O processo de hierarquia analítica (AHP) é um método heurístico popular baseado na ponderação aditiva, que calcula os fatores de ponderação associados às camadas de mapa de critério. Isso é alcançado usando uma matriz de referência onde todos os critérios relevantes, são comparados entre si com fatores de referência reproduzíveis (BANAI, 1993; WU, 1998; ZHU; DALE, 2001).

Aplicações AHP usando SIG tornaram-se um método comum de tomada de decisão devido à sua capacidade de integrar dados heterogêneos abundantes. O método AHP consiste em três etapas: (I) desenvolvimento da hierarquia AHP, (II) comparação par a par de elementos da estrutura hierárquica e (III) construção de uma classificação global de prioridade (BANAI, 1993; WU, 1998; ZHU; DALE, 2001).

Todos os fatores são classificados relativamente à importância da informação e proporciona a determinação da deformação Neotectônica. As classes são padronizadas para o mesmo intervalo de valores utilizando o procedimento WLC.

A padronização é baseada em um número de classes de cada fator em relação à importância das informações associadas com a Neotectônica, tais como as características geomorfológicas, estruturais e morfotectônicas. A determinação do peso de cada fator é obtida pela classificação e rank. Os fatores são classificados, com o valor mais alto sendo considerado o mais importante e o valor mais baixo o menos importante. Em seguida, a classificação é formada para cada fator usando percentuais (DROBNE; LISEC, 2009).

\subsection{Modelagem da Atuação Neotectônica}

Uma vez que os critérios para os fatores tenham sido padronizados e os pesos computados, aplicando a técnica WLC, se estabelecem critérios para formar uma única pontuação final de avaliação. Isso é feito por meio de uma sequência de multiplicações das matrizes de pesos relativos em cada nível da hierarquia. Como os valores dos critérios possuem escalas diferentes, é essencial uma abordagem padronizada dos fatores antes de sua combinação. Para a ponderação, levou-se em consideração a importância relativa de todos os fatores, regulando a compensação entre eles. O grau em que um fator pode compensar outro é determinado por seu fator ou compensação de peso. Dessa forma, os pesos foram gerados por uma série de comparações de pares de importância relativa de cada um dos fatores à adequabilidade dos pixels. A padronização é baseada no número de 
classes de cada fator em relação à importância da informação associada às atividades tectônicas (VOOGD, 1983; MALCZEWSKI, 2000; AYALEW et al, 2004).

A matriz resultante se denomina matriz de comparação pareada normalizada e é calculada por meio de cada fator das prioridades relativas dos elementos comparados, gerando peso para cada variável. Os resultados da matriz de comparação da importância relativa entre os fatores podem ser demonstrados em um quadro, onde todos os fatores ocuparão a primeira linha e a primeira coluna, possibilitando a comparação entre eles, de forma que na última linha seja expressa a soma dos diferentes valores, para as comparações par a par.

No método WLC, cada critério ponderado do par de pares é multiplicado pelo seu peso padronizado de classificação. Os resultados são somados e os índices usados aqui se concentram em zonas, de forma que os resultados indiquem o Índice de Deformação Neotectônica (NLDI):

$$
N L D I=\sum F w X F r
$$

onde Fw é o peso de cada fator e Fr é o rank padronizado de cada classe de fator. Depois de realizar o processo de ponderação de classificação para os valores de deformação Neotectônica, dentro da faixa de 0 a 100, a classificação será necessária para facilitar a interpretação.

Após a definição dos pesos de cada um dos critérios se procede a realização da modelagem com ferramenta complementar Weighted Overlay, instalada no ArcGIS. Esta técnica permite determinar a coerência dos resultados através do cálculo do coeficiente de consistência (CR). Se o resultado é $\mathrm{CR}<1$ indica que tem um nível razoável de consistência na comparação entre os pares, porém se $C R>1$, o valor da razão é indicativo de que se precisa reconsiderar e revisar os valores originais. A classificação final consistirá de classes: muito baixas, baixas, moderadas, altas e muito altas (AYALEW; YAMAGISHI; UGAWA, 2004). Na Figura 2, encontra-se um fluxograma de como os mapas foram combinados pelo processo de WLC, resultando um mapa final de modelagem do índice de deformação neotectônica.

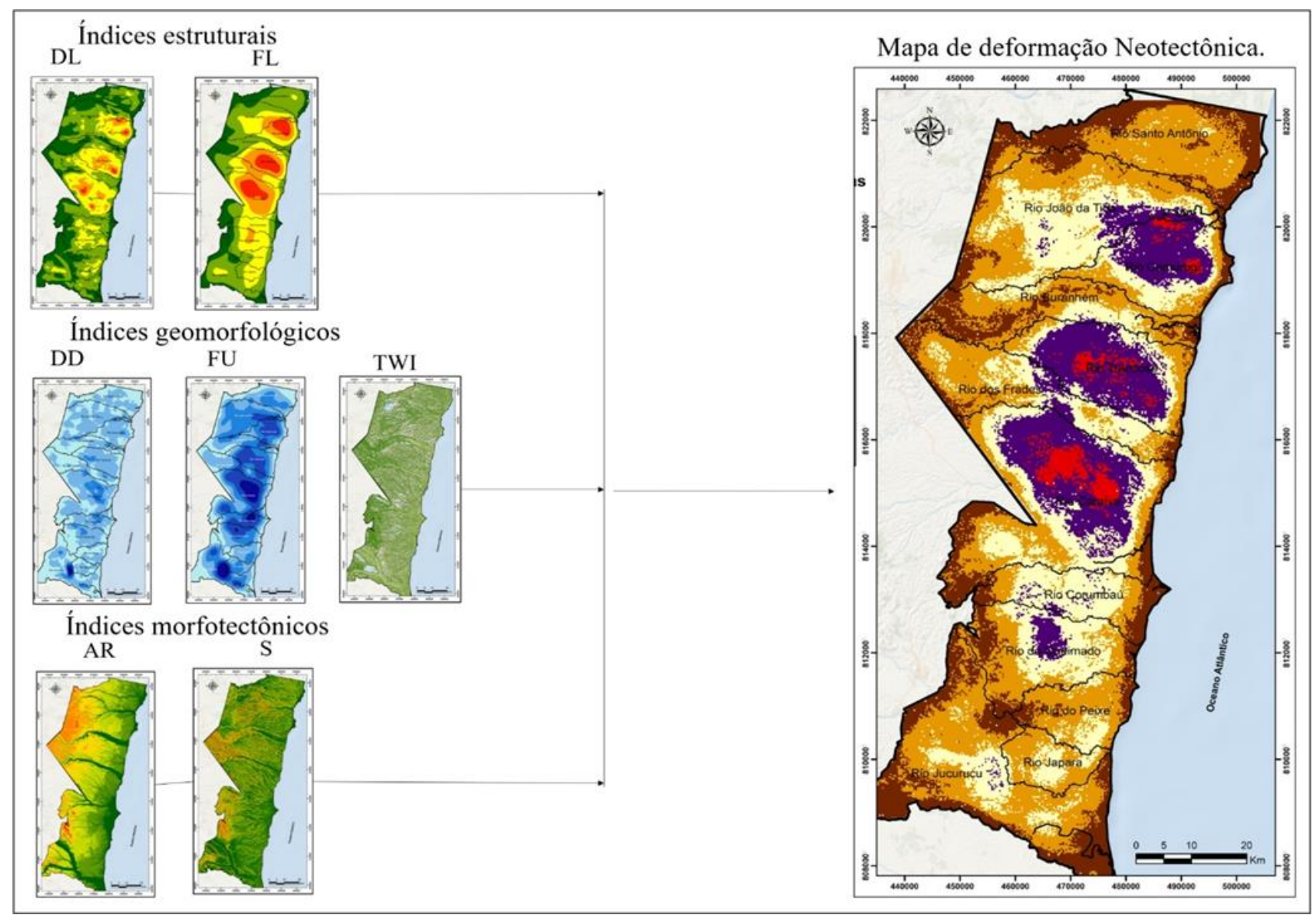

Figura 2. Fluxograma de modelagem do índice de deformação neotectônica, a partir dos índices estruturais, geomorfológicos e morfotectônicos. 


\section{Resultados e discussões}

Os trabalhos de campo foram desenvolvidos no Município de Porto Seguro e subdividido nos seguintes trechos: (1) Entre Arraial D'Ajuda e Trancoso, abrangendo o curso das bacias dos rios Buranhém, Trancoso, Frades e Caraíva (Figura 1). Nesse trecho foi identificado e medido um número significativo de estruturas que indicam a ação Neotectônica como juntas e em menor número, falhas geológicas. A forte influência das juntas, facilitam a percolação da água da chuva e aceleram o processo de erosão, provocando o deslocamento e queda de blocos e, consequentemente, o recuo das falésias (Figura 3A).

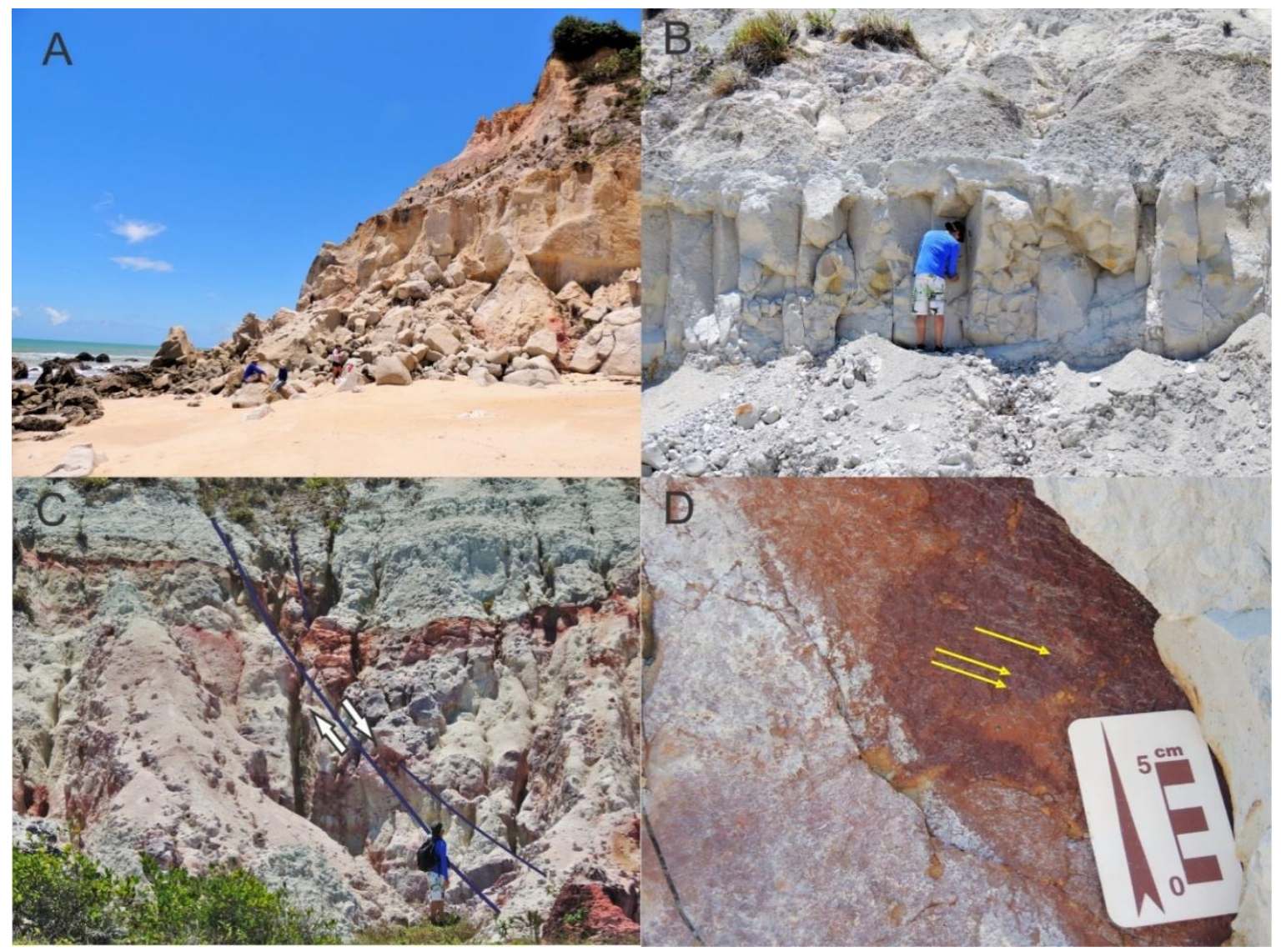

Figura 3. (A) Queda de blocos associados às juntas e falhas; (B) Sistema de juntas conjugadas, com direção predominante NW-SE e secundária NE-SW. (C) Falha normal observada nos sedimentos constituídos por uma intercalação entre camadas argilosas e arenosas friáveis. (D) Estrias de Falhas observadas nos afloramentos da Praia do Espelho ao norte de Caraíva.

Grande parte das falésias estudadas possui na base arcósiosareno-conglomeráticos, constituídos principalmente de grãos angulosos a subangulosos de quartzo e feldspato, podendo conter, em alguns locais, fragmentos de rochas cristalinas. Esse arcósio foi descrito por Lima, Vilas Boas e Bezerra (2006), que chamou a atenção para o fato dos feldspatos serem maiores que os grãos de quartzo, implicando em um transporte curto e soterramento rápido, o que aponta para a atuação de processos tectônicos durante o Neógeno, considerado aqui, como o período de deposição da Formação Barreiras (ROSSETTI; BEZERRA; DOMINGUEZ, 2013). Acima do arcósio, aparece uma intercalação entre camadas argilosas e arenosas friáveis, inibindo em muitos casos a preservação das juntas.

Em todas as áreas visitadas aparecem juntas tectônicas conjugadas, orientadas nas direções NW-SE e NE-SW embora no trecho entre Porto Seguro e Caraíva, tenha sido notável o incremento de faturamento (Figura 3B). Foram tomadas 492 medidas de juntas em toda área, com o predomínio das juntas NW-SE, ratificando os resultados encontrados em pesquisas anteriores (LIMA; VILAS BOAS; BEZERRA, 2006).

Falhas geológicas com direção predominante NE-SW foram observadas em vários locais. Nas falésias entre Porto Seguro e Trancoso foi possível observar falhas normais espaçadas em aproximadamente trinta metros, com planos de falhas atingindo continuidade por cerca de $10 \mathrm{~m}$. A feição mais notável é a de uma falha com rejeito de 
1,5 m e direção $\mathrm{N} 75^{\circ} \mathrm{E}$, mergulhando $60^{\circ} \mathrm{SE}$ (Figura 3C). Ao sul de Trancoso, foi identificado um aumento da densidade de falhas, no arcósio. Essas falhas têm menor persistência, direção NE-SW e mergulhos que variam de $40^{\circ}$ a $65^{\circ}$. Também foram observadas estrias sobre os planos de falha expostos por pressão e friç̧ões entre os blocos rochosos deslocados (Figura 3D).

Levando em consideração que a Formação Barreiras se depositou no Mioceno (ROSSETTI; GOES, 2009; ROSSETTI et al., 2011, 2013; GANDINI et al., 2017), a grande quantidade de estruturas rúpteis, como juntas e falhas, em sedimentos do Neógeno atestam uma tectônica pós-deposicional e consequentemente, considerada como neotectônica. Várias pesquisas têm interpretado a deformação, tanto rúptil, quanto dúctil em sedimentos da Formação Barreiras, como resultantes da Neotectônica. As deformações dúcteis seriam originadas por sismos, durante ou imediatamente após a deposição dos sedimentos, enquanto que as juntas e falhas seriam resultantes de eventos tectônicos posterior ao Mioceno, alguns datados do final do Pleistoceno (LIMA et al., 2014).

\subsection{Mapas de Índices estruturais}

Os lineamentos estruturais foram extraídos de imagens de satélite, por meio de duas bases distintas: uma imagem do satélite Landsat 8-OLI, aplicando a banda 8 (pancromática), e um mapa de relevo sombreado, com a utilização de diversos iluminantes, gerados a partir de imagens SRTM, com resolução de 30 metros. Os lineamentos identificados nas duas bases foram traçados diretamente no programa ArcMap, gerando dois mapas distintos. Finalmente os dados foram integrados para a criação de um mapa final.

Foi possível traçar 1630 lineamentos na área de estudo (Figura 4A). Os dados de lineamentos foram então processados pela ferramenta complementar AzimuthFinder (QUEIROZ; SALAMUNI; NASCIMENTO, 2014), instalada no ArcGIS, que fornece informações de orientação e dados de frequência. A plotagem dos lineamentos nos diagramas de rosetas, considerou a frequência de ocorrência, indicando uma maior frequência na direção NW-SE com 908 lineamentos (56\%) e uma frequência secundária na direção NE-SW com 722 lineamentos (44\%). Essas análises ratificam os resultados encontrados em pesquisas anteriores (LIMA; VILAS BOAS; BEZERRA, 2006), bem como os dados de campo coletados na nossa pesquisa.

Os resultados da análise da densidade e frequência de lineamentos podem ser visualizados nas Figuras 4B e 4C. Pelo observado no mapa, a grande densidade e frequência de lineamentos encontra-se nas bacias dos rios Camurugi, Trancoso e Caraíva, correspondendo a três blocos bem definidos estruturalmente. Esses três blocos estruturais foram definidos e interpretados anteriormente, por Lima, Vilas Boas e Bezerra (2006). Esta alta densidade e frequência de lineamentos indica alta influência do controle neotectônico nesse trecho da área estudada, atribuída a movimentos ocorridos no Pleistoceno, ou seja, posterior a todo processo deposicional. Por isso, surgiu a necessidade de estudá-los separadamente, para assim definir as direções mais frequentes, o número de lineamentos que eles contêm e uma comparação com os dados encontrados em campo (Figura 4D).

A bacia do Rio Camurugi (Figura 4D), consta de 272 lineamentos, representando 15\% do total, possuindo uma frequência de direção entre $\mathrm{N} 245^{\circ}-254^{\circ}$, ou seja, com uma orientação NE-SW. Em comparação com os dados

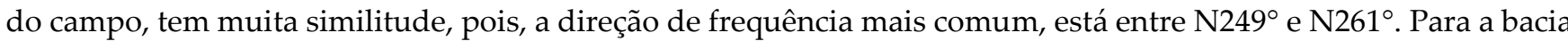
do Rio Trancoso (Figura 4D) foram encontrados 286 lineamentos, correspondendo a 17\% do total de lineamentos da área, possuindo direção predominante $\mathrm{N} 340^{\circ}-350^{\circ}$, com uma orientação NW-SE. Considerando o quadrante NW-SE, existe similaridade com os dados de campo, embora nesses últimos, a frequência predominante das juntas se direciona $\mathrm{N} 310^{\circ}-320^{\circ}$. E finalmente, para o último bloco, a bacia do Rio Caraíva (Figura 4D), com um total de 394 lineamentos, ou seja, $24 \%$ dos lineamentos da área, se determinou a frequência de direção $\mathrm{N} 150^{\circ}-160^{\circ}$, indicando uma orientação NW-SE, concordante com os resultados encontrados para a bacia do Rio Trancoso.

Não existe pesquisa que estabeleça os campos de tensão para Costa do Descobrimento. Entretanto, há uma similitude entre a disposição dos lineamentos observados nesta pesquisa e a distribuição de falhas observadas na Formação Barreiras, no Estado do Rio Grande do Norte (BEZERRA et al., 2001). Segundo esses autores, a orientação NE-SW e NW-SE das falhas apontam para uma compressão E-W e uma extensão N-S durante o Plioceno. A análise de imagens, bem como, os dados de campo da presente pesquisa mostram um predomínio de juntas NW-SE e falhas NE-SW, embora juntas NE-SW, também sejam muito comuns. Isso em princípio pode apontar para esforços compressivos, semelhantes aos encontrados para os depósitos do Neógeno no Rio Grande do Norte (BEZERRA et al., 2001). Por outro lado, dados estatísticos tomados a partir de juntas conjugadas, na Costa do Descobrimento, consideram essas estruturas, como resultantes de um esforço principal máximo $\left(\sigma_{1}\right)$ com direção NNW-SSE (N341º) e mergulho de 19ํ(IMA; VILAS BOAS; BEZERRA, 2006). 


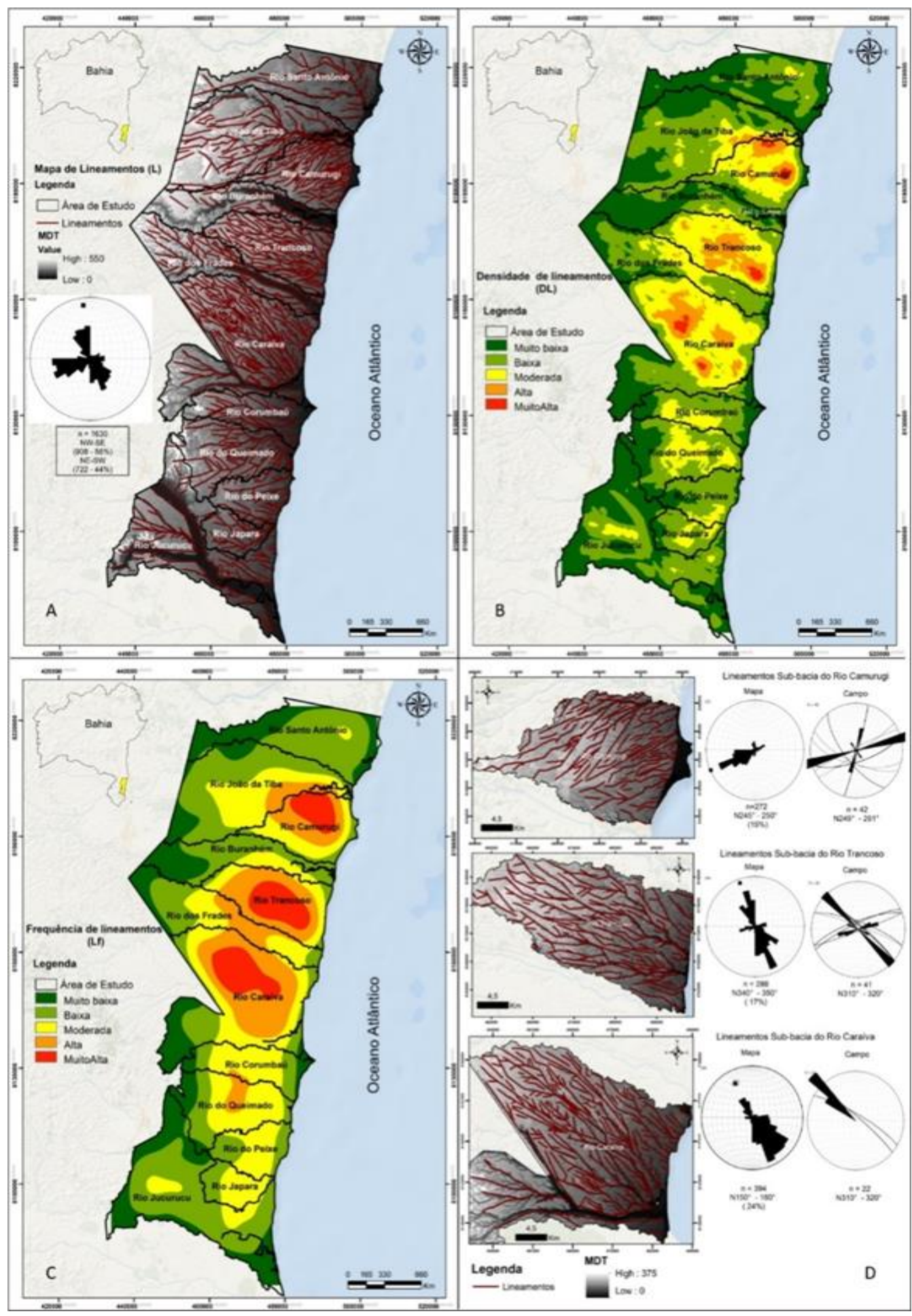

Figura 4. (A) Mapa de lineamentos (L). (B) Mapa de densidade de lineamentos (DL). (C) Mapa de frequência de lineamentos (FL). (D) Análise estrutural das bacias dos Rios Camurugi, Trancoso e Caraíva.

\subsection{Mapa de índices geomorfológicos}

A Figura 5A mostra o mapa de drenagem da área de estudo. A bacia do Rio Santo Antônio tem uma área total de $711,44 \mathrm{~km}^{2}$ e, desta, foram analisados $536,84 \mathrm{~km}^{2}$, o que equivale, a $75 \%$ da bacia. O padrão de drenagens predominante nessa bacia é o dendrítico, com os canais tributários se dispersando em várias direções formando ângulos agudos e nunca ângulos retos, o que pode indicar fenômenos tectônicos muito fracos ou inexistentes e baixo controle estrutural. Para a bacia do Rio João da Tiba, que possui uma área total $1588,54 \mathrm{~km}^{2}$, a análise realizada correspondeu a $47 \%$ do total, ou seja, $752,48 \mathrm{~km}^{2}$. O padrão da rede de drenagem é subdendrítico, com 
presença de canais meandrantes, principalmente no oeste da bacia, o que em princípio, caracteriza um baixo controle estrutural.

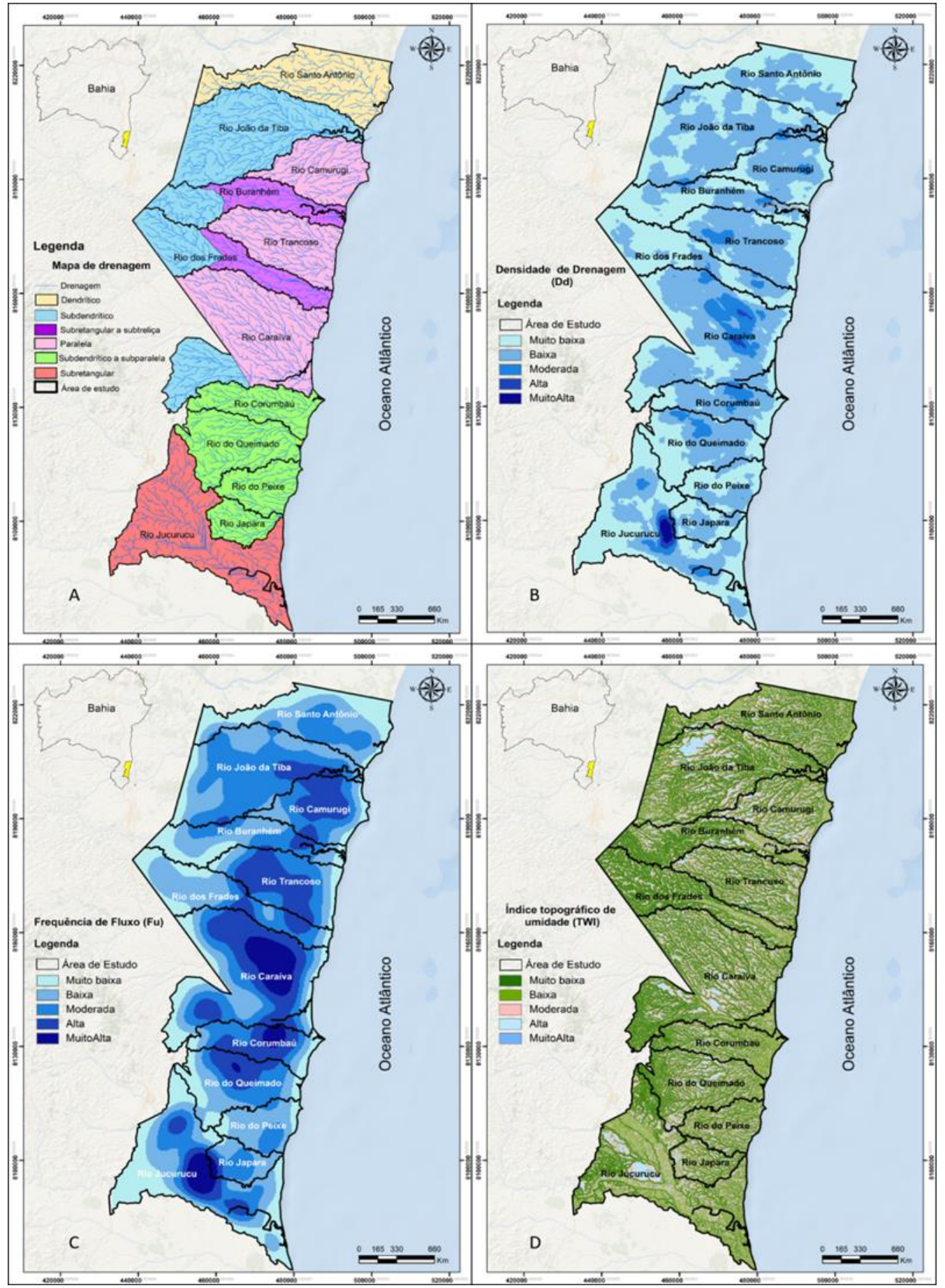

Figura 5. (A) Mapa de drenagem(D). (B) Mapa de densidade de drenagem (Dd). (C) Mapa de frequência de Fluxo (Fu). (D) Índice topográfico de umidade (TWI).

A bacia do Rio Camurugi inclui os rios Yaya, Mutari, Jardim, Mangues e Mundaí, que desembocam diretamente no Atlântico. Foi realizada a análise para a área total dessa bacia $\left(347,24 \mathrm{~km}^{2}\right)$, que apresenta, em maior proporção, uma distribuição paralela das drenagens que fluem para NE, indicando um controle no fluxo dos canais, seja topográfico ou estrutural. Pesquisas anteriores mostram os canais da Bacia Camurugi, com azimute médio de N70 (LIMA; VILAS BOAS; BEZERRA, 2006; LIMA; DOMINGUEZ, 2015). Essas pesquisas atribuem, tanto o padrão paralelo da drenagem, como a direção dos canais, a um basculamento de blocos ocorrido 
durante o Pleistoceno. O mesmo tipo de padrão de drenagem é observado na bacia do Rio Trancoso $\left(423,62 \mathrm{~km}^{2}\right)$, que contém também os rios da Barra e Ituípe. Esse padrão de drenagem tem uma orientação NW-SE, influenciado pelo controle topográfico imposto pela suave e contínua inclinação dos tabuleiros costeiros.

Da mesma forma anomalias similares das redes de drenagens foram reconhecidas nas bacias dos rios Buranhém e Frades, com destaque às mudanças nos padrões de drenagem e algumas mudanças bruscas no direcionamento dos canais. A análise dessas bacias foi realizada em áreas que correspondem respectivamente 19\% e 31\% no total da bacia. Na região leste das mesmas se identifica um padrão subretangular a subtreliça. Já para a região oeste ocorre uma mudança de configuração, passando a um padrão subdendrítico provocado, provavelmente, por controle estrutural fraco. As bacias do Buranhém e Frades diferem das demais bacias da área, por estarem limitadas a baixos estruturais com disposição E-W, interpretados como grabens (LIMA; DOMINGUEZ, 2015) e bordejados pelos maiores lineamentos observados na Costa do Descobrimento.

Exceto na região SW, que tem padrão subdendrítico, a bacia do Rio Caraíva impressiona, não só pelo paralelismo dos seus canais, mas também, pela persistência ao longo de cursos retilíneos, apontando para um forte controle estrutural. O tamanho total da bacia é de $1347,87 \mathrm{~km}^{2}$ e a análise da rede de drenagem foi de $65 \%$. Pesquisas anteriores mostram um azimute médio dos canais da bacia do Caraíva de N130 (LIMA; VILAS BOAS; BEZERRA, 2006; LIMA; DOMINGUEZ, 2015). Segundo esses autores, o bloco estrutural onde se instalou a bacia do Caraíva, sofreu um basculamento para SE durante o Pleistoceno. A análise das imagens desenvolvida em nossa pesquisa mostra que além do basculamento, existe um forte controle estrutural, onde vários canais estão inseridos em zonas de falhas e juntas. Os dados de campo referendam essa interpretação, já que há o predomínio de juntas com direção NW-SE. Além disso, o Rio Caraíva mostra em seu alto curso, fluxo para sudeste, em seu médio curso há uma mudança do fluxo para leste e finalmente, em seu baixo curso muda bruscamente para nordeste, fortalecendo a interpretação de controle estrutural em zonas de falhas.

Para as bacias dos rios Corumbau, Queimado, Peixe e Japara, foram analisadas suas áreas totais, onde observou-se na região leste um padrão subdendrítico e na porção oeste um padrão subparalelo, indicando uma forte inclinação dos terrenos nessas áreas, promovendo a mudança no padrão de drenagem. Finalmente a bacia do Rio Jucuruçu tem uma área total $2926,63 \mathrm{~km}^{2}$, e foram analisados $28 \%$ da mesma. Neste caso é possível observar que os canais apresentam um padrão de drenagem subretangular, típico de um controle estrutural ao longo de juntas e falhas.

Os resultados da análise da densidade de drenagem podem ser visualizados no mapa da Figura 5B. Pela análise do mapa, verifica-se que os valores menores de densidade estão distribuídos nas bacias dos rios Santo Antônio, Peixe, Japara, e oeste dos rios João da Tiba, Buranhém e Frades. Considerando somente a densidade de drenagem, esses valores apontam para uma menor influência da Neotectônica. As bacias dos rios Camurugi, Trancoso, Corumbau, Queimado e leste dos rios João da Tiba, Frades e Buranhém, evidenciam uma densidade de drenagem entre os intervalos de muito baixo a moderada. Finalmente os altos valores de densidade de drenagem (HORTON, 1945; BERGER; ENTEKHABI, 2001; AWASTHI et al., 2002) correspondem às bacias dos rios Caraíva e Jucuruçu, especificamente na porção NE, apontando assim para uma maior influência da Neotectônica.

O resultado do mapa de frequência de fluxo pode ser observado na Figura $5 \mathrm{C}$, onde os valores baixos estão distribuídos na parte oeste das bacias dos rios Buranhém e dos Frades, indicando terrenos com alta permeabilidade e capacidade de infiltração, o que pode indicar em princípio, baixa deformação Neotectônica. Já as bacias dos rios Camurugi, Trancoso, Peixe e Japara, e leste dos rios João da Tiba, Buranhém, Frades e oeste do Rio Caraíva, encontram-se no intervalo de frequência de fluxo de baixo a alto, resultando terrenos menos permeáveis com baixa capacidade de infiltração e alta erosão, apontando para uma deformação tectônica moderada. Por outro lado, foi observado um intervalo de alta frequência de fluxo, nas bacias Corumbau, Queimado, Jucuruçu e leste de Caraíva, indicando, em princípio, uma alta deformação tectônica, suficiente para modificar a rede de drenagem (KOULI et al., 2007).

A análise do mapa de índice topográfico de umidade (Figura 5D) revelou que a maior parte da área encontra-se com os valores baixos (tons verdes), mostrando um alto gradiente e baixa acumulação de umidade, formando parte de vales profundos, interpretados como características de tectônica ativa (BEVEN; KIRKBY,1979; SCHMIDT; PERSSON, 2003). É importante salientar que esses vales profundos estão bem definidos com padrão de drenagens paralelos e subparalelos na parte leste da área de estudo. Certamente os valores de moderados a muito altos de TWI, indicam uma baixa declividade e uma significativa acumulação de umidade, o que pode ser observado nas planícies de inundação dos grandes vales. 


\subsection{Mapa de indices Morfotectônicos}

A Figura 6A apresenta o mapa de amplitude de relevo (DELLA SETA et al., 2004; TROIANI; DELLA SETA, 2008) onde identificou-se na parte oeste da área estudada, uma altitude máxima de aproximadamente $550 \mathrm{~m}$, que para os autores Lima e Dominguez (2015), faz parte da área onde predomina embasamento cristalino que consiste em colinas e serras, com desníveis topográficos que podem atingir mais que $200 \mathrm{~m}$. Este relevo compõe os altos residuais do embasamento dissecado, com densidade de drenagem que varia de baixa a média. A dissecação intensa está relacionada aos lineamentos que exercem forte controle estrutural.

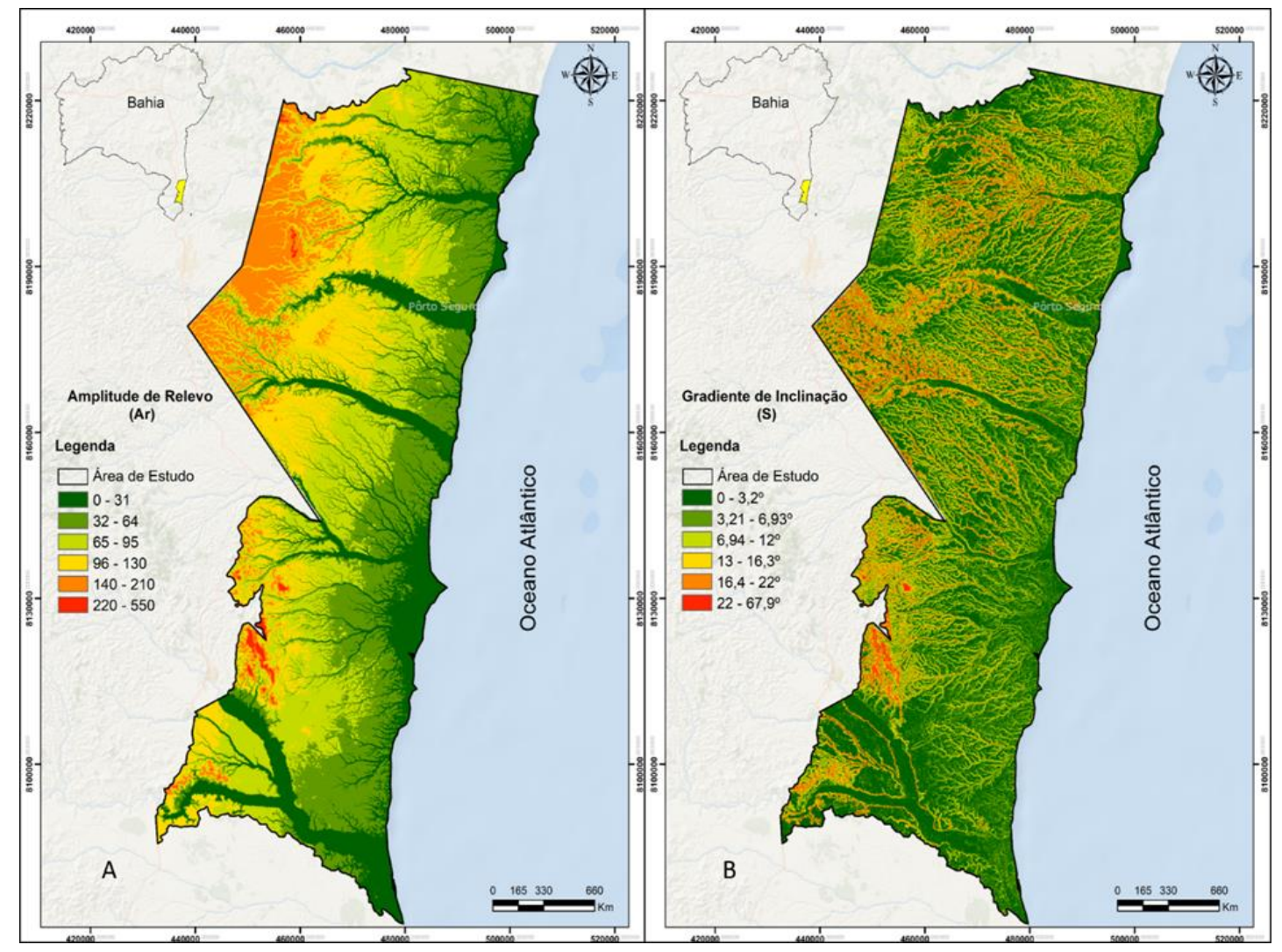

Figura 6. (A) Mapa de amplitude de revelo. (B) Mapa de gradiente de Inclinação

A leste do embasamento cristalino, encontram-se unidades geomorfológicas denominadas superfícies colinosas (DANTAS; MEDINA, 2000). A amplitude de relevo varia entre 40 a $80 \mathrm{~m}$, podendo aparecer escarpas degradadas com desníveis significativos $(60$ a $100 \mathrm{~m})$, caracterizado pelo recuo erosivo das escarpas estruturais produzidas pela Neotectônica ao longo do médio curso dos vales principais na região (Figura 6A).

Em seguida na parte leste da área se encontram os tabuleiros costeiros, que variam em largura entre 20 e 100 $\mathrm{km}$ e exibem terreno plano com um leve gradiente em direção ao mar. Nos tabuleiros costeiros, a densidade de drenagem varia de média a alta e promove dissecação uniforme do relevo, com vales rasos que se aprofundam em direção à costa e são cercados por encostas convexas curvas (MENDES; DANTAS; BEZERRA, 1987).

Analisando o mapa de gradiente de inclinação (Figura 6B) observa-se que a declividade varia de 0 a $68^{\circ}$. A maior parte da área de estudo possui uma declividade variando de 0 a $12^{\circ}$, refletindo a morfologia predominantemente tabular, constituídas por superfícies planas, não dissecadas pela rede de canais. Além desse valor, outro que se destaca é o intervalo de 13 a $22^{\circ}$, identificando morfologicamente os tabuleiros dissecados que consistem de colinas tabulares de topos planos a levemente arredondados, frequentemente sulcados por uma densa rede de pequenos canais, apresentando vales encaixados de pequena profundidade. Em seguida, o intervalo de 23 a $68^{\circ}$, que indica as maiores declividades da área, além de um forte indício da influência tectônica (EVANS, 1979; PANIZZA, 1996). Encontram-se nesses intervalos as escarpas degradadas e as colinas tabulares caracterizadas por vales profundos e encaixados no embasamento, o que denota forte controle estrutural produzido por processos tectônicos que remontam à origem das rochas e possivelmente a reativações posteriores. 


\subsection{Modelagem e Análise da Neotectônica}

A modelagem da atuação da Neotectônica foi realizada, utilizando-se a técnica de comparação de pares do módulo Weight, possibilitando a geração de um conjunto de pesos relativos pra cada um dos fatores que foram agregados no processo de combinação linear ponderada (WLC). As variáveis utilizadas para esta comparação de pares foram densidade de lineamentos (DL), frequência de lineamentos (FL), densidade de drenagem (DD), frequência de fluxo (FU), índice topográfico de umidade (TWI), amplitude de relevo (AR) e gradiente de inclinação (S) e a importância relativa e os pesos gerados para cada variável estão apresentados na Tabela 3.

Tabela 3. Matriz de comparação da importância relativa dos fatores par a par. DL: densidade de lineamentos, FL: frequência de lineamentos, DD: densidade de drenagem, FU: frequência de fluxo, TWI: índice topográfico de umidade, AR: amplitude de relevo, S: gradiente de inclinação.

\begin{tabular}{|c|c|c|c|c|c|c|c|c|c|c|c|c|}
\hline & DL & FL & & DD & & FU & & TWI & & AR & & $\mathrm{S}$ \\
\hline DL & 1 & 2 & & $1 / 2$ & & $1 / 2$ & & $1 / 5$ & & $1 / 3$ & & $1 / 7$ \\
\hline FL & $1 / 2$ & 1 & & $1 / 7$ & & $1 / 5$ & & $1 / 5$ & & $1 / 4$ & & $1 / 6$ \\
\hline DD & 2 & 7 & & 1 & & 3 & & 2 & & 2 & & $1 / 2$ \\
\hline FU & 3 & 5 & & $1 / 3$ & & 1 & & 3 & & 2 & & $1 / 2$ \\
\hline TWI & 5 & 5 & & $1 / 2$ & & $1 / 3$ & & 1 & & 3 & & $1 / 2$ \\
\hline AR & 3 & 4 & & $1 / 2$ & & $1 / 2$ & & $1 / 3$ & & 1 & & $1 / 2$ \\
\hline$S$ & 7 & 6 & & 2 & & 2 & & 2 & & 2 & & 1 \\
\hline Soma & $21 \quad 1 / 2$ & 30 & 4 & $41 / 42$ & 7 & $8 / 15$ & 8 & $11 / 15$ & 10 & $7 / 12$ & 3 & $13 / 42$ \\
\hline
\end{tabular}

Os dados da Tabela 4 mostram que o processamento de dados de múltiplos critérios, a partir do processo de hierarquia analítica e da análise por combinação linear ponderada (WLC), apontam para uma maior influência dos de índices estruturais, como a densidade de lineamentos (DL) com um peso de 27,33 e a frequência de lineamentos (FL) com 21,35. Para os critérios de índices geomorfológicos a densidade de drenagem tem um peso de 15,61; frequência de fluxo de 16,99; e por último, o índice topográfico de umidade com 10,34. Já os índices morfotectônicos tiveram pesos menores, com 5,34 e 2,98 para amplitude de relevo e gradiente de inclinação respectivamente. A análise dos resultados para o coeficiente de consistência (CR) mostra que dos dados são bastante consistentes, já que o CR é igual a 0,13, um número bem abaixo de 1 e próximo de zero.

Tabela 4. Definição do Coeficiente de consistência (CR), destacando os parâmetros considerados, com seus respectivos pesos.

\begin{tabular}{ccc}
\hline Coeficiente de consistência (CR) & Critérios & Pesos \\
\hline & DL & 27,33 \\
& FL & 21,35 \\
0,13 & DD & 15,61 \\
$(\mathrm{CR}<1$ tem um ótimo nível de & FU & 16,99 \\
consistência na comparação entre os pares) & TWI & 10,34 \\
& AR & 5,34 \\
& S & 2,98 \\
& Total & 100 \\
\hline
\end{tabular}

O domínio dos índices estruturais e geomorfológicos sobre os índices morfotectônicos ocorre provavelmente, pelo fato da maior parte da área estar coberta por tabuleiros costeiros com baixa inclinação. Isso vai influenciar a amplitude de relevo, já que esse índice tem como base a configuração orográfica de uma área e representa a distribuição da tectônica ativa, avaliando-se o relevo relativo de uma região (DELLA SETA et al., 2004; TROIANI; DELLA SETA, 2008). A uniformidade do relevo, também vai diminuir a influência do gradiente de inclinação (EVANS, 1979; PANIZZA, 1996), já que não possibilita a formação de knickpoints (TROIANI et al., 2014) e por 
isso, diminui o peso do gradiente de inclinação, frente aos outros índices adotados para a interpretação da neotectônica.

A modelagem da atuação da Neotectônica (Figura 7) tem como resultado os níveis de deformação tectônica muito baixa, baixa, moderada, alta e muito alta, mostrando os registros neotectônicos mais evidentes, contribuindo assim, com o planejamento de ocupação e gerenciamento dessas áreas.

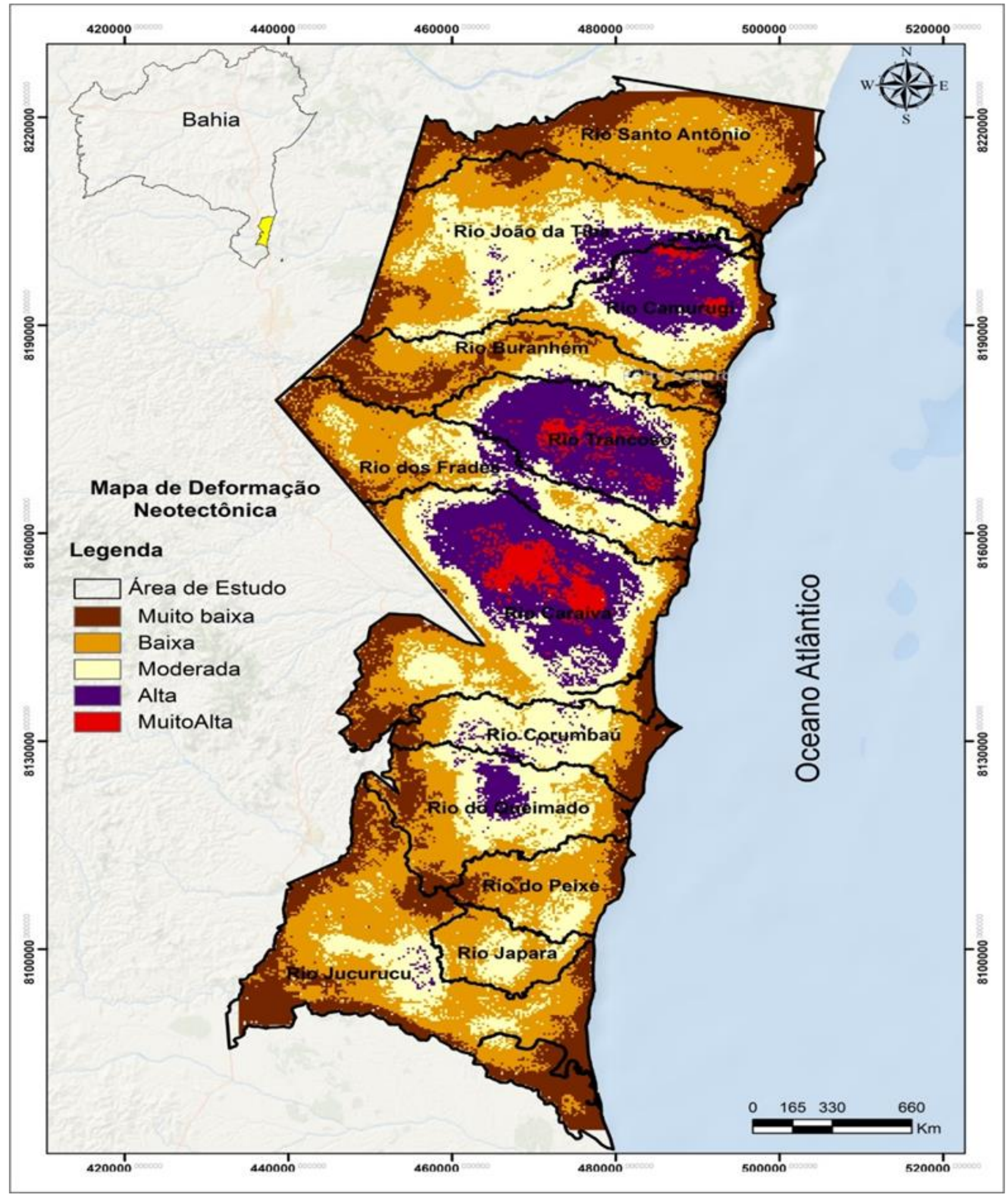

Figura 7. Modelagem da deformação neotectônica. O mapa destaca as bacias dos rios Camurugi, Trancoso e Caraíva, como tendo uma deformação tectônica muito alta e o Rio Queimado, com moderada a alta deformação tectônica. 
Com os níveis muito baixos e baixos de deformação encontram-se as bacias dos Rios Santo Antônio, Peixe, e porção oeste das bacias dos Rios Buranhém, Frades e Jucuruçu. Para os níveis de baixo a moderado estão as bacias dos Rios Corumbau, Japara e parte do Jucuruçu e do João da Tiba. Para a bacia do Rio Queimado existe uma moderada a alta influência tectônica.

A modelagem da neotectônica mostra níveis mais altos nas bacias dos rios Camurugi, Trancoso e Caraíva. Essas bacias são separadas por baixos estruturais interpretadas como grabens (LIMA; VILAS BOAS; BEZERRA, 2006; LIMA e DOMINGUEZ, 2015). As falhas que bordejam esses grabens são as que possuem maior persistência na Costa do Descobrimento e a reativação dessas zonas de fraqueza, durante eventos tectônicos do Pleistoceno, promoveram o basculamento dos blocos, a formação dos sistemas de juntas conjugadas nos depósitos do Neógeno, além da criação de espaço, para o estabelecimento dos grabens onde se instalaram as bacias dos rios Buranhém e Frades.

\section{Conclusões}

Os trabalhos de campo, bem como a análise dos índices estruturais, geomorfológicos e morfotectônicos mostraram que eventos neotectônicos atuaram na Costa do Descobrimento, promovendo a reativação de falhas, o basculamento de blocos, originando sequências conjugadas de juntas. Os dados de múltiplos critérios processados a partir da hierarquia analítica e da análise por combinação linear ponderada (WLC) mostram que, para a área estudada, há um domínio dos índices estruturais e geomorfológicos sobre os índices morfotectônicos. Essa resposta aos índices trabalhados se deve, à grande concentração de lineamentos, representados por juntas e falhas, fazendo com que, tanto o mapa de densidade, quanto o de frequência de lineamentos, tivessem um peso maior no método trabalhado.

Atrelados aos índices estruturais, os índices geomorfológicos, representados pela densidade de drenagem, frequência de fluxo e índice topográfico de umidade, também tiveram pesos significativos. Isso é justificado, já que a maior parte da drenagem da Costa do Descobrimento, teve seus padrões modificados, pelos eventos tectônicos que bascularam os blocos estruturais por onde fluem os rios. Além disso, parte da drenagem segue os cursos das zonas de fraqueza, ou seja, tem controle estrutural, seja por falhas ou juntas. Vale ressaltar, que há uma correlação direta entre os grandes vales da área, interpretados como grabens e os lineamentos mais persistentes observados. A conjunção desses fatores, promoveu o estabelecimento das bacias dos rios Buranhém e Frades e basculou os blocos adjacentes que mostram, no mapa da atuação Neotectônica, as bacias com os valores mais altos de deformação. Sãos elas, as bacias dos rios Camurugi, Trancoso e Caraíva.

Os índices morfotectônicos, amplitude de relevo e gradiente de inclinação tiveram pesos baixos na confecção do mapa de deformação neotectônica. Isso se deve à uniformidade do relevo dominado por tabuleiros com baixa declividade. Independente dessa resposta ao método, os pesos dos índices morfotectônicos, aplicados devidamente em conjunto com os demais índices resultaram em um coeficiente de consistência de 0,13, o que confirma a eficácia da metodologia empregada.

A integração dos mapas destacando os índices estruturais, geomorfológicos e morfotectônicos, mostrou ser um método eficaz para a confecção do mapa da deformação Neotectônica e abre possibilidades para que outros estudos possam se desenvolver ao longo de áreas costeiras. Além disso, a metodologia pode ser uma alternativa de baixo custo para detectar zonas de deformação tectônica, em diferentes terrenos, tendo sempre em mente, que o peso dos índices vai variar, de acordo com os aspectos geológicos, estruturais e geomorfológicos de cada área pesquisada. Finalmente, a metodologia é uma ferramenta potencialmente útil, auxiliando no planejamento de uso e ocupação de áreas suscetíveis a riscos geológicos.

Contribuições dos Autores: Oriana Isabel Rojas González -Concepção; metodologia; uso de software e validação; pesquisa e curadoria de dados; preparação e redação do artigo; revisão e edição do texto. Carlos César Uchôa de Lima -Concepção; metodologia; validação; pesquisa e curadoria de dados; preparação e redação do artigo; revisão e edição do texto; supervisão; aquisição de financiamento.

Financiamento: Este trabalho foi possível graças à bolsa de mestrado oferecida pela CAPES (Coordenação de Aperfeiçoamento de Pessoal de Nível Superior), à primeira autora deste artigo e à Pró Reitoria de Pós Graduação e Pesquisa da Universidade Estadual de Feira de Santana (UEFS), pelo financiamento parcial das viagens de campo.

Agradecimentos: Os autores agradecem aos revisores anônimos pelas valiosas sugestões, que muito contribuíram para a melhoria do manuscrito. Também à CAPES (Coordenação de Aperfeiçoamento de Pessoal de Nível Superior), pela bolsa de mestrado da primeira autora. À Organização dos Estados Americanos, que proporcionou a vinda da primeira autora, da 
Venezuela para o Brasil. E, finalmente, ao professor Ardemírio Barros da Silva, pelo seu honroso auxílio no processamento de dados de múltiplos critérios e na análise por combinação linear ponderada.

Conflito de Interesse: Os autores declaram não haver conflito de interesse quanto à publicação do artigo "Modelagem espacial da neotectônica na costa do descobrimento, sul do estado da Bahia".

\section{Referências}

1. ANANABA, S. E.; ANJAKAIYE, D. E. Evidence of tectonic control of mineralization in Nigeria from lineament density analysis a Landsat-study. International Journal of Remote Sensing, v. 8, n. 10, p. 1445-1453. 1987. DOI: 10.1080/01431168708954788

2. ARGYRIOU A.; TEEUW R. M.; RUST D.; SARRIS A. GIS multi-criteria decision analysis for assessment and mapping of neotectonic landscape deformation: A case study from Crete. Gemorphology, v. 253, p. 262-274. 2015. DOI: 10.1016/j.geomorph.2015.10.018

3. AYALEW, L.; YAMAGISHI, H.; UGAWA, N. Landslide susceptibility mapping using GIS based weighted linear combination, the case in Tsugawa area of Agano River, Niigata Prefecture, Japan. Landslides, v. 1, p. 73-81. 2004. DOI: 10.1007/s10346-003-0006-9

4. AWASTHI, K. D.; SITAULA, B.K.; SINGH, R. B. R.; BAJACHARAYA, M. Land-use change in two Nepalese watersheds: GIS and geomorphometric analysis. Land Degrad. Develop, v. 13, p. 495-513. 2002. DOI: 10.1002/ldr.538

5. BANAI, R. Fuzziness in geographic information systems: contributions from the analytic hierarchy process. International Journal of Geographical Information Systems. v. 7 (4), p. 315-329. 1993. DOI: 10.1080/02693799308901964

6. BERGER, K. P.; ENTEKHABI, D. Basin hydrologic response relations to distributed physiographic descriptors and climate. Journal of Hydrology, v. 247, p. 169-182. 2001. DOI 10.1016/S0022-1694(01)00383-3

7. BEVEN, K. J.; KIRKBY, M. J. A physically based, variable contributing area model of basin hydrology. Hydrol. Sci.Bull. v. 24, p. 43-69. 1979. DOI: 10.1080 / 02626667909491834

8. BEZERRA, F. H. R.; VITA-FINZI, C. How active is a passive margin? Paleoseismicity in northeastern Brazil. Geology, v. 28, p. 591- 594. 2000. DOI: 10.1130/0091-7613(2000)28

9. BEZERRA, F. H. R.; AMARO, V. E.; VITA-FINZI, C.; SAADI, A. Pliocene-Quaternary fault control of coastal plain morphology and sedimentation in northeastern Brazil. Journal of South American Earth Sciences, v. 14, p. 61-75. 2001 DOI: 10.1016/S0895-9811(01)00009-8

10. BEZERRA, F. H. R.; FONSECA, V. P.; VITA-FINZI, C.; LIMA-FILHO, F. P.; SAADI, A. Liquefaction-induced structures in Quaternary alluvial gravels and gravelly sediments. Engineering Geology, v. 76, p. 191-208. 2005. DOI: 10.1016/j.enggeo.2004.07.007

11. BRIERE, P. R.; SCANLON, K.M. Lineaments and lithology derived froma side-looking airborne radar image or Puerto Rico. Puerto Rico-marine Sediment Database, Terrestrial and Sea-floor Imagery and Tectonic Interpretations: U.S. Geological Survey Open-File Report 00-006. 2000.

12. BULL, W.; MCFADDEN, L. Tectonic geomorphology north and south of the Garlock Fault, California. In: DOEHRING, D. O. (Ed.). Geomorphology in Arid regions. 1 ${ }^{\mathrm{a}}$ Ed. Londres: Routledge, 1977. p. 115-139. DOI: 10.4236/ojg.2015.53010

13. CBPM. Projeto Costa do Descobrimento. Salvador: CBPM, 2000.

14. CHANG, H. K.; KOWSMANN, R. O.; FIGUEIREDO, A. M. F.; BENDDER, A. A. Tectonics and stratigraphy of the east Brazil Rift System: an overview. Tectonophysics, v. 213 (1-2), p. 97-138, 1992. DOI: 10.1016/0040-1951(92)

15. COSTA, J. B. S.; BEMERGUY, R. L.; HASUY, Y.; BORGES, M. S. Tectonics and Paleogeography along the Amazon river. Journal of South American Earth Sciences, v. 14, p. 335-347, 2001. DOI: 10.1016/S0895-9811(01)00025-6

16. DANTAS, M. E.; MEDINA, A. I. M. Geomorfologia. Projeto Porto Seguro/Santa Cruz Cabrália. Salvador: CPRM-SUREG/SA. 2000.

17. DELLA SETA, M.; DEL MONTE, M.; FREDI, P.; LUPIA PALMIERI, E. Quantitative morphotectonic analysis as a tool for detecting deformation patterns in soft-rock terrains: a case study from the southern Marches, Italy. Géomorphologie: relief, processus, environnement, n. 4, p. 267-284, 2004. DOI: 10.3406/morfo.2004.1224

18. DINESH, A. C.; MARKOSE VIPIN, J.; JAYAPPA, K.S. Info a visual basic program for lineament density, frequency and intersection density analysis. Earth Sci. Inform. v. 7, p. 197-203, 2014. DOI: 10.1007/s12145-013-0134-2

19. DOMINGUEZ, J. M. L. Evolução quaternária da planície costeira associada à foz do rio Jequitinhonha (BA): influência das variações do nível do mar e da deriva litorânea dos sedimentos. Salvador. Dissertação (Mestrado em Geologia) Instituto de Geociências, Universidade Federal da Bahia, Salvador. 1983. 73p.

20. DROBNE, S.; LISEC, A. Multi-attribute decision analysis in GIS: weighted linear combination and ordered weighted averaging. Informatica, v. 33, p. 459-474, 2009. 
21. EVANS, I. S. An integrated system of terrain analysis and slope mapping. Final Reporton Grant DA-ERO-591-73-G0040. University of Durham, England, 192p. 1979. DOI: 10.1111 / j.1558-5646.1979

22. FONSECA, V. P. Estudos morfotectônicos aplicados à planície costeira do Rio Grande do Sul. Tese (Doutorado em Geociências) - Programa de Pós-Graduação em Geociências, Universidade Federal do Rio Grande do Sul, Porto Alegre, 2006. 307p.

23. FREITAS, R. O. Ensaio Sobre o Relevo Tectônico do Brasil. Rev. Bras. de Geograf., v. 2, p. 171-221. 1951. DOI: 10.11606/issn.2526-3862.bffcluspgeologia.1951.121701

24. GANDINI, R.; ROSSETTI, D. F.; NETTO, R. G.; GÓES, A.M. A Miocene wave-dominated estuarine system in the Paraíba Basin, northeastern Brazil. Journal of South American Earth Sciences, v. 79, p. 264-280. 2017. DOI: 10.1016/j.yqres.2014.07.003

25. HASUI, Y. Neotectônica e Aspectos Fundamentais da Tectônica Ressurgente no Brasil. SBG/MG. Workshop sobre Neotectônica e Sedimentação Cenozoica Continental no Sudeste Brasileiro, Belo Horizonte, 1, 1-31. 1990.

26. HORTON, R. E. Erosional development of streams and their drainage basins; hydrophysical approach to quantitative morphology. Geol. Soc. Am. Bull. v. 56, p. 275-370. 1945. DOI: 10.1177/030913339501900406

27. KELLER, E. A. Investigation of active tectonics: use of surficial earth processes. In: WALLACE, R. E. (Ed.). Active Tectonics. Studies in Geophysics. 1ํㅡㄹ Ed. Washington: The National Academies Press, 1986. p. 136-147.1986. DOI: 10.17226/624. . $^{-}$

28. KING, L. C. A. Geomorfologia do Brasil Oriental. Rev. Bras. Geogr. v. 2, p. 147-265, 1956.

29. KOULI, M.; VALLIANATOS, F.; SOUPIOS, P.; ALEXAKIS, D. GIS-based morphometric analysis of two major watersheds, western Crete. Greece, Journal of Environmental Hydrology, v. 15, p. 1-17. 2007. DOI: 0.1007/s12665-014-3389-0

30. LIMA, C. C. U. O neotectonismo na costa do sudeste e do nordeste brasileiro. Revista de Ciência e Tecnologia, v. 8, p. 91-101, 2000.

31. LIMA, C. C. U. Evidências da ação tectônica nos sedimentos da Formação Barreiras presentes do litoral de Sergipe ao norte da Bahia. Rev. Geogr., v. 1, p. 140-151 (Recife: UFPE, DCG/NAPA, v. Especial, VIII SINAGEO), 2010.

32. LIMA, C. C. U.; VILAS BOAS, G. S.; BEZERRA, F. H. R. Faciologia e análise tectônica Preliminar da formação Barreiras no litoral sul do Estado da Bahia. Geologia USP. Série Científica, v. 6, n. 2, p. 71-80, 2006. DOI: 10.5327/s1519-874x2006000300009

33. LIMA, C. C. U.; BEZERRA, F. H. R.; NOGUEIRA, F. C. C.; MAIA, R. P.; SOUSA, M. O. L. Quaternary fault control on the coastal sedimentation and morphology of the São Francisco coastal plain, Brazil. Tectonophysics, v. 633, p. 98-114, 2014. DOI:10.1016/j.tecto.2014.06.026

34. LIMA, C. C. U.; DOMINGUEZ, J. M. L. DISCOVERY COAST: The Brazilian landscape first sighted by Europeans. In, VIEIRA, B. C.; SALGADO, A. A. R.; SANTOS, L. J. C. Landscapes and Landforms of Brazil. SpingerVerlag, p. 45-54. 2015.

35. MALCZEWSKI, J. On the use of Weighted Linear Combination method in GIS: common and best practise approaches. Trans. GIS, v. 4, p. 5-22, 2000. DOI: 10.1111/1467-9671.00035

36. MENDES, I.; DANTAS, M.; BEZERRA, L. M. M. Geomorfologia. In: IBGE. Folha SE-24 Rio Doce: geologia, geomorfologia, pedologia, vegetação, uso potencial da terra. Rio de Janeiro, p. 548, 1987.

37. MOLIN, P.; PAZZAGLIA, F. J.; DRAMIS, F. Geomorphic expression of active tectonics in arapidly-deforming forearc, Sila massif, Calabria, southern Italy. Am. J. Sci, v. 304, p. 559-589, 2004. DOI: 10.2475/ajs.304.7.559

38. NEVES J. M. C, SOARES A. C. P.; MARCIANO V. R. P. R. O. A província pegmatítica oriental do Brasil à luz dos conhecimentos atuais. Rev Bras Geoc, v. 16(1), p. 106-118, 1986. DOI:10.25249/0375-7536.1986106118

39. PANIZZA, M. Environmental Geomorphology. 1ํㅡㄹ Ed. Elsevier Science, 1996. 288p. DOI: 10.1016/s0928-2025(96)80016-2

40. PAVLIDES, S. B. Looking for a definition of neotectonics. Terra Nova, v. 1, n. 3, p. 233-235, 1989. DOI: 10.1111/j.1365-3121.1989.tb00362.x

41. PÉREZ-PEÑA, J. V.; AZAÑÓN, J. M.; AZOR, A.; DELGADO, J.; GONZÁLEZ-LODEIRO, F. Spatial analysis of stream power using GIS: SLk anomaly maps. Earth Surf. Process. v. 34, p. 16-25, 2009. DOI: 10.1002/esp.1684

42. QUEIROZ, G. L.; SALAMUNI, E.; NASCIMENTO, E. R. AzimuthFinder: ferramenta para a extração de dados e apoio na análise estrutural. Geol. USP, Sér. cient., v. 14(1), p. 6-80, 2014. DOI: 10.5327/z1519-874x201400010005

43. RAMÍREZ-HERRERA, M. T. Geomorphic assessment of active tectonics in the Acambay Graben, Mexican volcanic belt. Earth Surf. Process, v. 23, p. 317-332. 1998. DOI: 10.1002/(sici)1096-9837(199804)23:4<317::aid-esp845>3.0.c0;2-v

44. ROSSETTI, D. F.; GÓES, A. M. Marine influence in the Barreiras Formation, State of Alagoas, northeastern Brazil. Anais da Academia Brasileira de Ciências, v. 81(4), p. 741-755, 2009. DOI: 10.1590/S0001-37652009000400012 
45. ROSSETTI, D. F.; BEZERRA, F. H. R.; GÓES, A. M.; NEVES, B. B. B. Sediment deformation in Miocene and post-Miocene strata, Northeastern Brazil: Evidence for paleoseismicity in a passive margin. Sedimen. Geol, v. 235, p. 172-187, 2011. DOI: 10.1016/j.sedgeo.2010.02.005

46. ROSSETTI, D. F.; BEZERRA, F. H. R.; DOMINGUEZ, J. M. L. Late Oligocene-Miocene transgressions along the equatorial and eastern margins of Brazil. Earth Science Reviews, v. 123, p. 87-112, 2013. DOI: 10.1016/j.earscirev.2013.04.005

47. ROCKWELL, T. K.; KELLER, E.A.; JOHNSON, D. L. Tectonic geomorphology of alluvial fans and mountain fronts near Ventura, California. In: MORISAWA, M.; HACK, T.J. (Eds.), Tectonic Geomorphology. 1ㄹ Ed. Binghamton: Publ. in Geomorphology, University of New York, 1984. p. 183-207, DOI: 10.4236/ojg.2015.53010 3,720

48. SAADI, A. Neotectônica da área dos tabuleiros do sul da Bahia. PROJETO Porto Seguro: Santa Cruz Cabrália: programa informações para gestão territorial. Salvador: CPRM: CBPM: SEAGRI-DDF, p. 40-55. 2000.

49. SCHMIDT, F.; PERSSON, A. Comparison of DEM data capture and topographic wetness indices. Preci. Agric. v. 4, p. 179-192, 2003. DOI: 10.1023/a:1024509322709

50. SELEEM, T. A. Analysis and tectonic implication of DEM-derived structural lineaments. Sinai Peninsula, Egypt, International Journal of Geosciences, v. 4, p. 183-201, 2013. DOI: 10.4236/ijg.2013.41016

51. SILVA, P.; GOY, J.; ZAZO, C.; BARDAJI, T. Fault-generated mountain fronts in southeast Spain: geomorphologic assessment of tectonic and seismic activity. Geomorphology, v. 50, p. 203-225, 2003. DOI: 10.1016/s0169-555x (02)00215-5

52. SUGUIO, K.; MARTIN, L. The Role of Neotectonics in the Evolution of the Brazilian Coast. Geonomos, v. 4 (2), p. 45-53, 1996.

53. SUMMERFIELD, M. A. Geomorphology and Global Tectonics. 1aㅗ Ed. John Wiley \& Sons, 2000. p. 386. DOI: $10.1017 / \mathrm{s} 0016756800244610$

54. TOUDESHKI, V. H.; ARIAN, M. Morphotectonic analysis in the GhezelOzan River Basin, NW Iran. Journal of Geography and Geology, v. 3, p. 258-265, 2011. DOI: 10.5539/jgg.v3n1p258

55. TROIANI, F.; DELLA SETA, M. The use of the stream length gradient index in morphotectonic analysis of small catchments: a case study from Central Italy. Geomorphology, v. 102, p. 159-168, 2008.2 DOI: 10.1016/j.geomorph.2007.06.020

56. TROIANI, F.; GALVE, J. P.; PIACENTINI, D.; DELlA SETA, M.; GUERRERO, J. Spatial analysis of stream length-gradient (SL) index for detecting hillslope processes: A case of the Gállego River headwaters (Central Pyrenees, Spain). Geomorphology, v. 214, p. 183-197, 2014. DOI:10.1016/j.geomorph.2014.02.004

57. TSODOULOS, I. M.; KOUKOUVELAS, I. K.; PAVLIDES, S. Tectonic geomorphology of the easternmost extension of the Gulf of Corinth (Beotia, Central Greece). Tectonophysics, p. 211-232, 2008. DOI: 10.1016/j.tecto. 2007. 06.015

58. VAN DER BEEK, P.; CHAMPEL, B.; MUGNIER, J. L. Control of detachment dip on drainage development in regions of active fault propagation folding. Geology, v. 30, p. 471-474, 2002. DOI: 10.1130/0091-7613(2002)030<0471: coddod>2.0.co;2

59. VOOGD, H. Multicriteria Evaluation for Urban and Regional Planning. $1^{\text {a }}$ Ed. Londres: Pion Ltd, 1983. p. 367. DOI: $10.1080 / 00420988420080891$

60. WELLS, S. G.; BULLARD, T. F.; MENGES, T. M.; DRAKE, P. G.; KARAS, P. A.; KELSON, K. I.; RITTER, J. B.; WESLING, J. R. Regional variations in tectonic geomorphology along segmented convergent plate boundary, Pacific coast of Costa Rica. Geomorphology, v. 1, p. 239-265, 1988. DOI: 10.1016/0169-555x (88)90016-5

61. WU, F. SimLand: a prototype to simulate land conversion through the integrated GIS and CA with AHP-derived transition rules. Int. J. Geogr. Inf. Sci. v. 12, p. 63-82, 1998. DOI: 10.1080/136588198242012

62. ZHU, X.; DALE, A. P. JavaAHP: a Web-based decision analysis tool for natural resource and environmental management. Environ. Model. Softw. v.16, p. 251-26, 2001. DOI: 0.1016/s1364-8152(00)00082-7.

Esta obra está licenciada com uma Licença CreativeCommons Atribuição 4.0 Internacional (http://creativecommons.org/licenses/by/4.0/) - CC BY. Esta licença permite que outros distribuam, remixem, adaptem e criem a partir do seu trabalho, mesmo para fins comerciais, desde que lhe atribuam o devido crédito pela criação original. 